\title{
Electrochromic Performances of Conductive Polyaniline Copolymer
}

\author{
N. Thummarungsan and D. Pattavarakorn
}

\begin{abstract}
The conductive polyaniline copolymer films were fabricated and their electrochromic performances were investigated. The polyaniline copolymer was synthesized through an oxidative coupling polymerization and doped with sulfuric acid dopant. Copolymer thin films were then prepared via solution casting on ITO plastic substrate. The electrochromic properties were examined using 1.0 M sulfuric acid as electrolyte. The electrochromic performances of copolymer films were further determined by measuring electrochromic photographs and UV absorption spectra. The results showed that polyaniline copolymer was successfully synthesized in which its chemical structure was confirmed by FTIR. In addition, the color of copolymer thin film turned from green to blue under the applied potential. It was also found that the copolymer films exhibited highest optical contrast at the applied potential equal to 3 volts. Moreover, the optical contrast and response time trend to depend on acid dopant concentration and applied potential.
\end{abstract}

Index Terms-Electrochromic, conductive polymer, doping, polyaniline.

\section{INTRODUCTION}

Conductive polymers such as polyaniline, polypyrrole and polythiophene have been interested in recent decades, due to their potential applications, e.g. electromagnetic shielding, rechargeable, antistatic coating and electrochromic devices [1], [2].

Polyaniline (PANi) is one of the most widely studied conductive polymers due to its relative high conductivity, facile synthesis, environmental, stability and unique electronic properties. One especially which makes PANi different from other conductive polymers is that PANi can be made conductive by protic acid doping and can be dedoped to produce the neutral emeraldine base form of PANi (EB). The neutral PANi thus prepared is doped again by reacting with counter anions to produce the doped conductive PANi as shown in Scheme 1 [3].

Polyaniline in the emeraldine base state is an important conductive polymer for technological applications. However, the poor solubility of PANi in common organic solvents has limited its practical applications in many fields. Recently, electroactive polymers (i.e., polyamide and polyimide) incorporated with aniline oligomer have attracted research attention because of their superior properties such as good solubility, mechanical strength and ability to form film [4],

Manuscript received September 9, 2013; revised November 23, 2013. This study was supported financially by the Center of Excellence in Materials Science and Technology, Faculty of Science and the Graduated School, Chiang Mai University.

The authors are with the Chiang Mai University, Faculty of science, Department of Industrial Chemistry, Chiang Mai 50200, Thailand (e-mail: datchanee.p@cmu.ac).
[5]. Hueng et al. have developed oxidative coupling polymerization to synthesize copolymer of oligoaniline and p-phenylenediamine. The resulting copolymer contains superior corrosion inhibition and electrochromic properties [6].

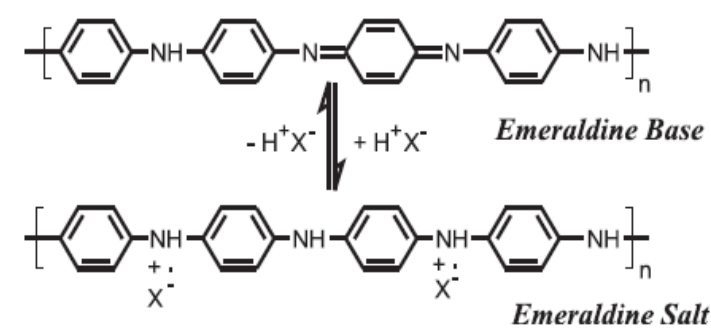

Scheme 1. Doping of polyaniline with counter anions [3].

In the present study, preparation of conductive polyaniline copolymer films via solution casting on ITO plastic substrate was investigated. The electrochromic performances; optical contrast and response time of conductive polyaniline copolymer films were investigated in terms of acid dopant concentration and applied potential.

\section{EXPERIMENTAL}

\section{A. Materials}

$\mathrm{N}$-phenyl-p-phenylene diamine (Aldrich), sebacoyl chloride (Aldrich) and p-phenylenediamine (Aldrich) were used as monomers. Triethylamine (Merck) and ammonium persulfate (APS, Aldrich) were used as alkaline agent and oxidant, respectively. Ammonium hydroxide (J.T. baker) and hydrazine hydrate (Aldrich) were used as reducing agent. N-methyl-2-pyrrolidone (NMP, Merck), dichloromethane (Labscan) and ether (J.T. baker) were used as solvents. Sulfuric acid (Labscan) was used as dopant. The $60 \Omega$ indium tin oxide (ITO) coated PET (Aldrich) was used as substrate for film casting.

\section{B. Synthesis of Polyaniline Copolymer (LB) Form}

Polyaniline copolymer powders were chemically synthesized according to the method described by Hueng et al. [6]. The fine powders of $0.4 \mathrm{~g}$ polyaniline copolymer (EB) was dispersed in solution consisting of $4 \mathrm{ml}$ hydrazine hydrate and $40 \mathrm{ml} 1.0 \mathrm{M}$ ammonium hydroxide under vigorous stirring for about $10 \mathrm{~h}$. Then, the reaction mixture was filtered and washed several times with distilled water. Finally, the obtained polyaniline copolymer in the luecoemeraldine base (LB) form was dried under vacuum at $40{ }^{\circ} \mathrm{C}$ for $24 \mathrm{~h}$.

\section{Preparation of Polyaniline Copolymer Doped Film}

Polyaniline copolymer (LB) films were prepared by 
dissolving $0.1 \mathrm{~g}$ polyaniline copolymer (LB) powder in $2 \mathrm{ml}$ NMP. An acid dopant; sulfuric acid was added. The molar ratio of polyaniline copolymer (LB) to acid dopant was varied as 1:0.5, 1:1 and 1:5. After that, the solutions were drop-casted onto ITO plastic $(1 \mathrm{~cm} \times 5 \mathrm{~cm})$ and dried under vacuum at $60{ }^{\circ} \mathrm{C}$ for $30 \mathrm{~min}$ to remove the solvent.

\section{Characterization}

The chemical structure of the polyaniline copolymer powder was examined by Fourier-transform infrared spectroscopy, FTIR (Perkin-Elmer, Perkin-Elmer model spectrum RX I) in order to characterize their molecular structures. The surface morphology of the polyaniline copolymer powder and films were investigated using SEM (Jeol, JSM 5910LV) technique.

The thermal stability of the polyaniline copolymer powder was investigated using thermogravimetry, TGA (Rigaku, TG 8120 ), in which samples were heated from 25 to $900{ }^{\circ} \mathrm{C}$ at a heating rate of $10^{\circ} \mathrm{C} / \mathrm{min}$. All measurements were conducted under nitrogen atmosphere.

\section{E. Electrochromic Performance Measurement}

Electrochromic properties of sulfuric acid doped PANi copolymer films were determined using electrochromic photographs (Canon, IXUS 115 HS) and UV-visible spectrometer (Hewlett packaro). Measurements were assembled as an electrochemical with the PANi copolymer film coated ITO plastic as the cathode electrode, the stainless steel wire as the anode electrode, and $0.1 \mathrm{M}$ sulfuric acid as electrolyte solution as shown in Fig. 1 [7], [8].

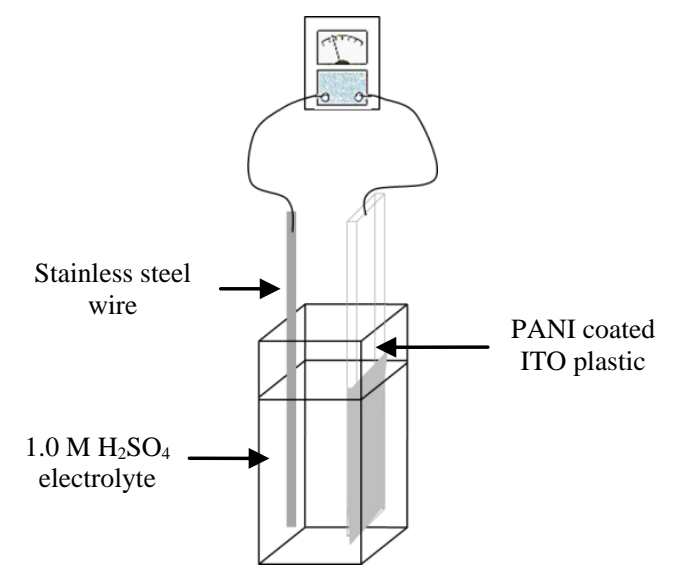

Fig. 1. The schematic of PANi copolymer electrochemical cell.

\section{RESUlts AND Discussion}

\section{A. Characteristics of Polyaniline Copolymer Ppowder and Films}

The chemical structures of PANi copolymer (EB) and sulfuric acid doped PANi copolymers were examined by FTIR spectroscopy, the spectra have been shown in Fig. 2. The copolymers exhibit the characteristic absorption peak at $3200-3400 \mathrm{~cm}^{-1}$ relates to the N-H stretching of benzenoid and quinoid rings. The peaks around $2800-3000 \mathrm{~cm}^{-1}$ can be assigned to the $\mathrm{C}-\mathrm{H}$ stretching vibration. The peak at 1655 $\mathrm{cm}^{-1}$ can be attributed to the $\mathrm{C}=\mathrm{O}$ stretching vibration. The important peaks at $1597 \mathrm{~cm}^{-1}$ and $1510 \mathrm{~cm}^{-1}$ corresponse to the $\mathrm{C}=\mathrm{C}$ stretching deformation of the quinoid $(\mathrm{N}=\mathrm{Q}=\mathrm{N})$ and benzenoid (N-B-N) rings, respectively. The absorption peak at $1300 \mathrm{~cm}^{-1}$ assigns to $\mathrm{C}-\mathrm{N}$ stretching mode of vibration and the peak at $821 \mathrm{~cm}^{-1}$ can be corresponded to the out of plane bending vibration [6]. For the sulfuric acid doped PANi, the main characteristic peak has been found at around $1170 \mathrm{~cm}^{-1}$ which can be assigned to $\mathrm{SO}_{2}$ stretching vibration [9].

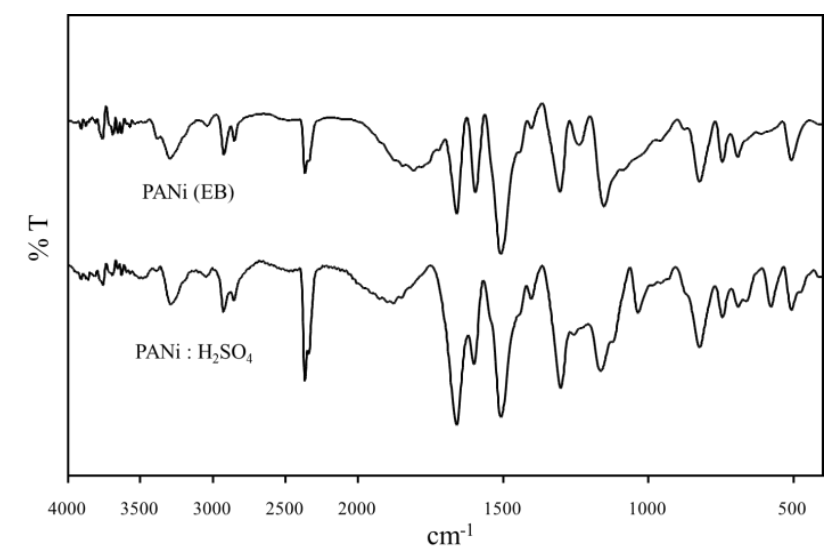

Fig. 2. FTIR spectra of PANi copolymer (EB) and sulfuric acid doped PANi copolymer.

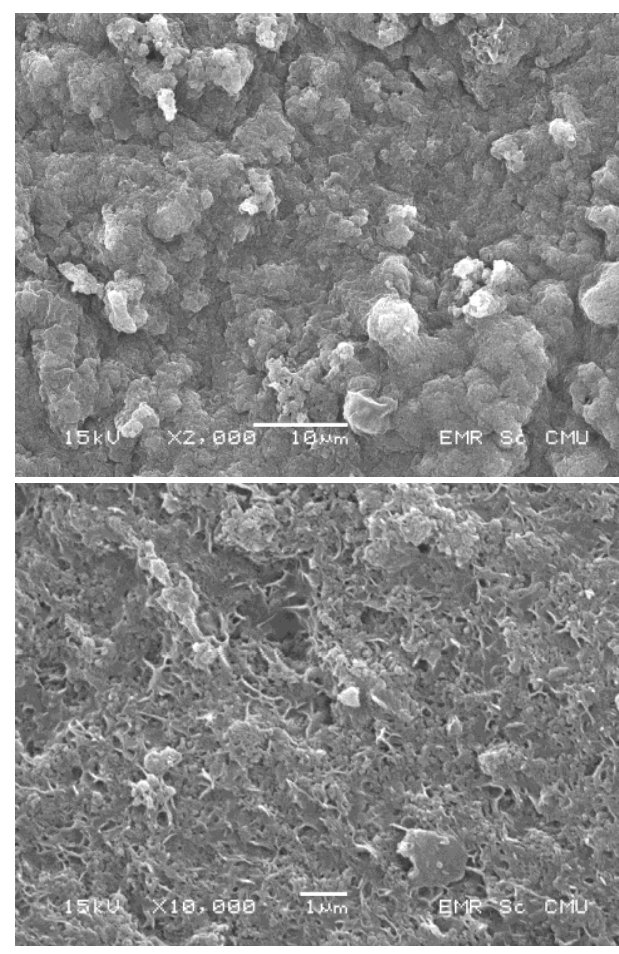

Fig. 3. SEM photographs of PANi copolymer (EB) powder.

Scanning electron micrographs of PANi copolymer (EB) powders are shown in Fig. 3. The SEM shows that PANi copolymer particles appear to be irregular shape and aggregate. Fig. 4 shows morphology of sulfuric acid doped PANi copolymer film upon the application of applied potential 0 and $2.0 \mathrm{~V}$. At $0 \mathrm{~V}$, it can be clearly observed that surface of the sulfuric acid doped PANi copolymer film are smooth and more regular. After the application of $2.0 \mathrm{~V}$ applied potential, $\sim 1 \mu \mathrm{m}$ tiny-flake can be observed on film surface.

The thermal properties of PANi copolymer powders have been investigated using TGA as shown in Fig. 5. The TGA thermogram of PANi copolymer (EB) powder shows three 
important weight losses in the derivatives curves. The first weight loss at $250-350{ }^{\circ} \mathrm{C}$ probably assigns to the structural decomposition of amine group in polymer backbone. The second weight loss is observed at around $370-520{ }^{\circ} \mathrm{C}$ corresponses to decomposition effects of PANi polymer. Above $600{ }^{\circ} \mathrm{C}$, the results obtained are associated with the polymer residues only [10]

After doping with sulfuric acid dopant, doped PANi copolymers show four degradation steps. The first state at approximately $160{ }^{\circ} \mathrm{C}$ is due to the start of the removal of dopant molecules [11]. The other three states accord to the degradation of amine group, PANi and polymer residues which occur at around 270,380 , and $600^{\circ} \mathrm{C}$, respectively.
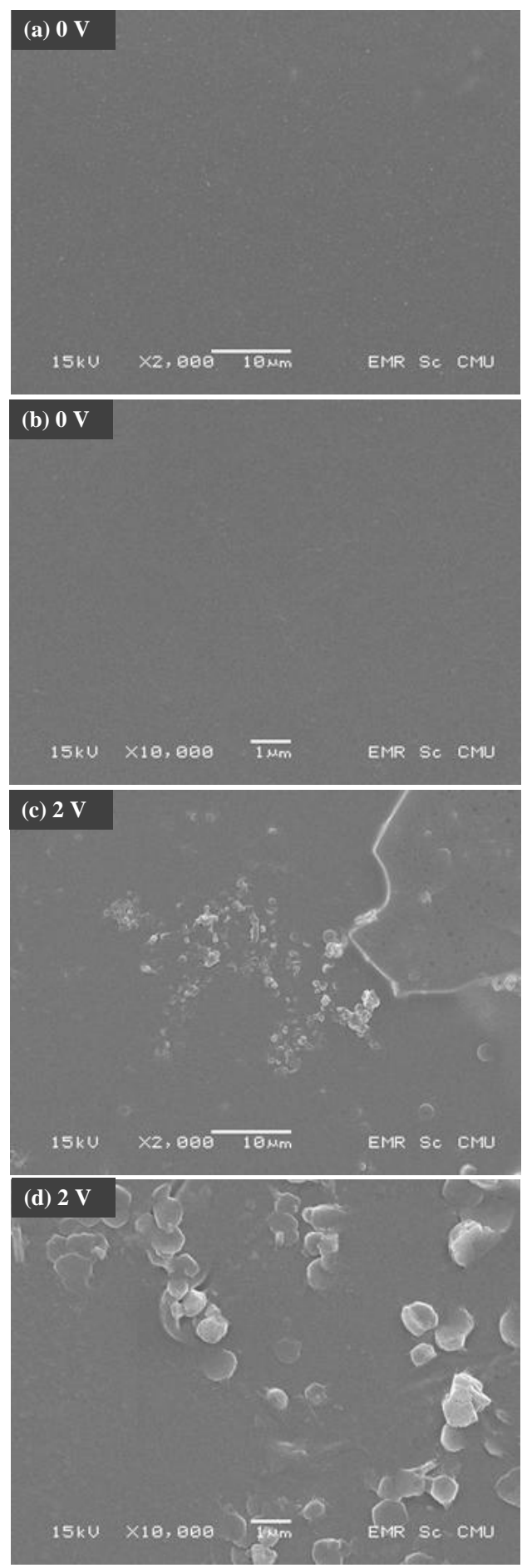

Fig. 4. SEM photographs of PANi copolymer $(a, b)$ and sulfuric acid doped PANi copolymer films (c, d) upon applied potential 0 and $2.0 \mathrm{~V}$.

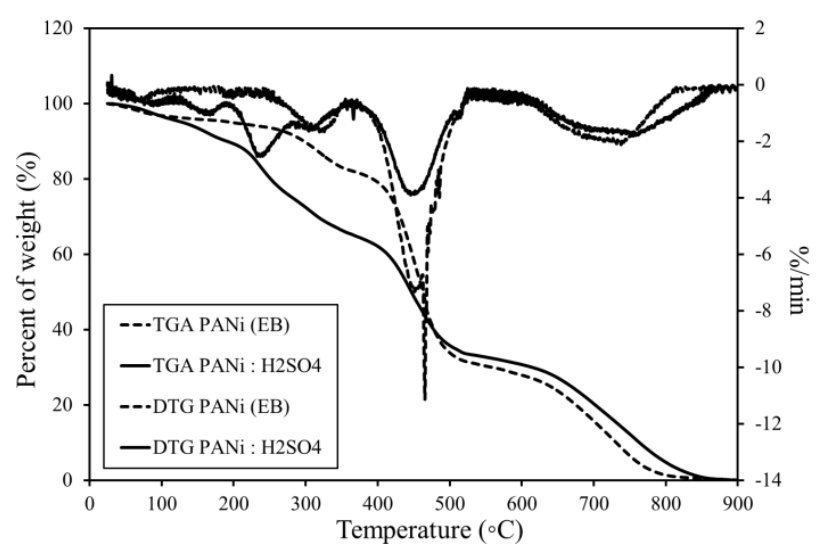

Fig. 5. TGA and DTG thermograms of PANi copolymer (EB) and sulfuric acid doped PANi copolymers.

\section{B. Electrochromic Performances}

The sulfuric acid doped PANi copolymer films with various PANi:dopant concentration ratios were prepared by drop-casting onto ITO plastic substrate. The electrochromic performances of the doped films were investigated under the application of electrical voltages. The effects of acid dopant concentration and applied potential were examined. The results show that color of the films turn from green to blue under the applied potential. Fig. 6 shows the electrochromism of $0.1 \mathrm{M}$ sulfuric acid doped PANi copolymer films at $3.0 \mathrm{~V}$ applied potential (vs. Pt electrode). The light green color can be observed in reduction state, $0 \mathrm{~V}$. With $3.0 \mathrm{~V}$ applied potential, oxidized state, color of the doped film becomes dark blue. The color change of sulfuric acid doped PANi films corresponds to the different structures of PANi; leucoemeraldine base (LB), emeraldine base (EB), and pernigraniline base (PNB), as shown in Scheme 2 [6].
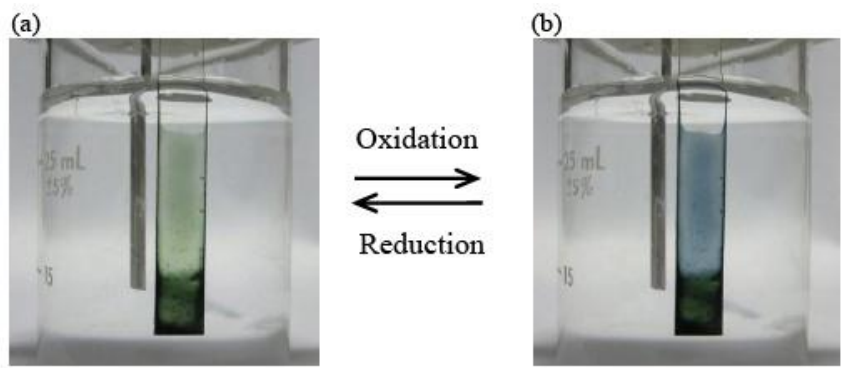

Fig. 6. Electrochromism of $0.1 \mathrm{M} \mathrm{H}_{2} \mathrm{SO}_{4}$ doped PANi copolymer film at (a) 0 $\mathrm{V}$ and (b) $3.0 \mathrm{~V}$ (vs. Pt electrode)

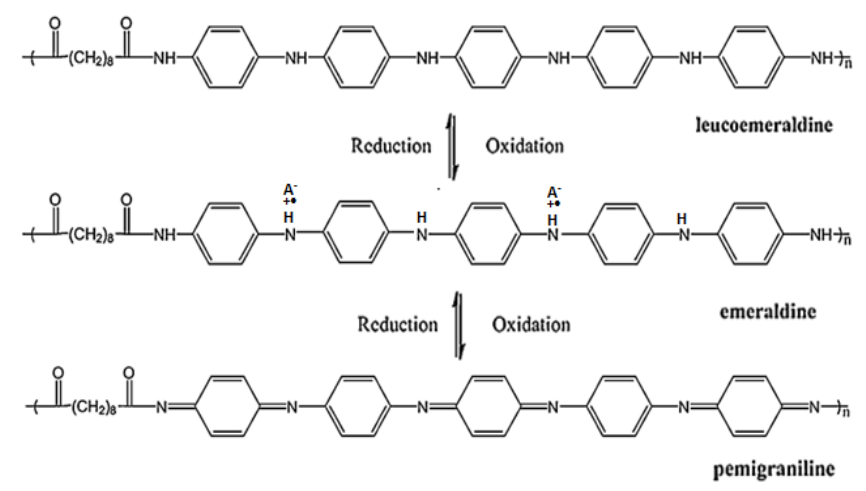

Scheme 2. Molecular structures of the PANi copolymer at various oxidation states [6]. 
Furthermore, the electrochromic response time of PANi copolymer films was carried out by electrochromic photograph test. The results according to the effects of PANi: $\mathrm{H}_{2} \mathrm{SO}_{4}$ concentration ratio and applied potential were tabulated in Table I and Table II, respectively. It was found that higher PANi: $\mathrm{H}_{2} \mathrm{SO}_{4}$ ratio resulted in faster response time in which the sulfuric acid doped PANi copolymer film with PANi: $\mathrm{H}_{2} \mathrm{SO}_{4}$ concentration ratio equals to $1: 5$ exhibited the fastest response time, $0.28 \mathrm{~s}$. For the effects of applied potential, the fastest response time, $0.3 \mathrm{~s}$, was observed at 2.0 $\mathrm{V}$ applied potential.

TABLE I: RESPONSE TIME OF SULFURIC ACID DOPED PANI FILMS AT \begin{tabular}{|c|c|} 
VARIOUS PANI: $\mathrm{H}_{2} \mathrm{SO}_{4}$ CONCENTRATION RATIOS AT $2.0 \mathrm{~V}$ \\
\hline $\begin{array}{c}\text { Concentration ratio of } \\
\text { PANi/dopant }\end{array}$ & Response time (sec) \\
\hline $1: 0.5$ & 0.57 \\
\hline $1: 1$ & 0.30 \\
\hline $1: 5$ & 0.28 \\
\hline
\end{tabular}

TABLE II: RESPONSE TIME OF SULFURIC ACID DOPED PANI FILMS AT VARIOUS APPLIED POTENTIALS (PANI: $\mathrm{H}_{2} \mathrm{SO}_{4}=1: 1$ )

\begin{tabular}{|c|c|}
\hline Potential (V) & Response time $(\mathrm{sec})$ \\
\hline 1.0 & 8.00 \\
\hline 2.0 & 0.30 \\
\hline 3.0 & 0.47 \\
\hline 4 & 0.35 \\
\hline 5 & 0.40 \\
\hline
\end{tabular}

In addition, the optical contrast $\left(\Delta T \%=T_{\max }-T_{\min }\right)$ of electrochromic properties of sulfuric acid doped PANi copolymer films under various potentials was investigated by UV-visible spectrometry. The absorbance spectra of sulfuric acid doped PANi copolymer films at different applied potentials are shown in Fig. 7. It was observed that the strong absorption at wavelengths of 440 and $580 \mathrm{~nm}$ gradually increases with the increase of applied potentials from $1.0 \mathrm{~V}$ to $3.0 \mathrm{~V}$. The absorbances correspond to green and blue color regions of the visible spectrum in reduced state and oxidized state, respectively. It was also found that the absorbance at $580 \mathrm{~nm}$ decreases when the applied potential higher than 3.0 V.

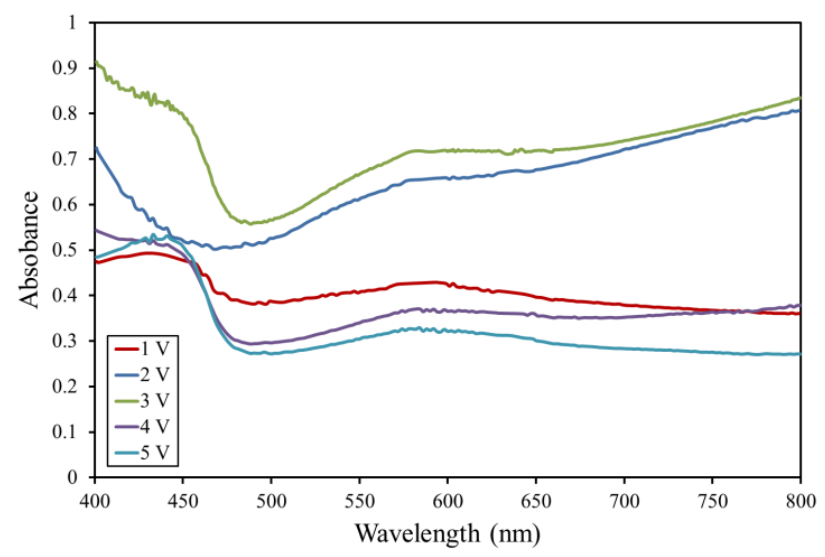

Fig. 7. The absorption spectra of sulfuric acid doped PANi copolymer films at various applied potentails.

Fig. 8 shows the transmittance, $\% \mathrm{~T}$ of the sulfuric acid doped PANi copolymer films at reduced state and oxidized state. It can be seen that the electrochromic optical contrast of the sulfuric acid doped PANi copolymer films at wavelength of $430 \mathrm{~nm}$ and $680 \mathrm{~nm}$ are approximately $2 \%$ and $3 \%$, respectively.

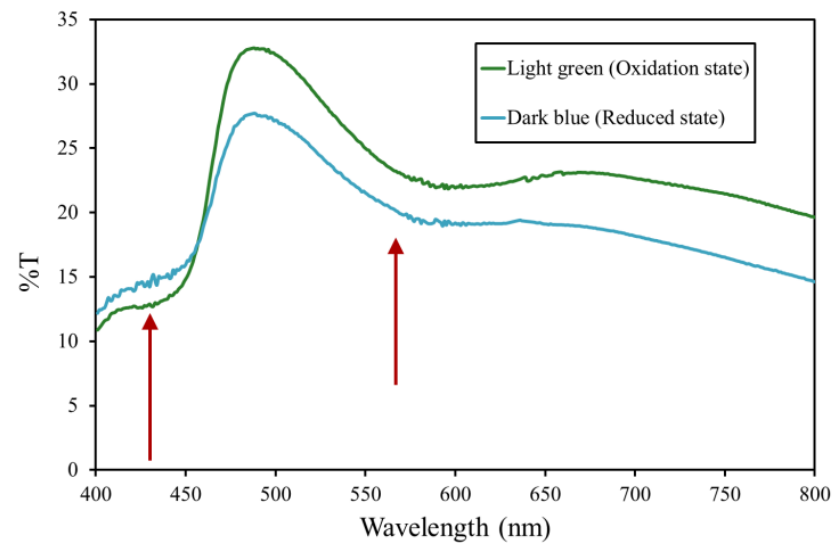

Fig. 8. Transmittance spectra at reduced state and oxidized state of sulfuric acid doped PANi copolymer films.

\section{CONCLUSION}

The electrochromic performances of the sulfuric acid doped PANi copolymer films was investigated. The conductive polyaniline copolymer was synthesized and then doped with sulfuric acid dopant. The films were prepared by solution drop-cast onto ITO plastic substrate. The effects of dopant concentration and applied potential on electrochromic performances of the films were determined. It was found that color of the film changes from light green to dark blue under the application of applied potential. The fastest response time, $0.28 \mathrm{~s}$, observed from the film with PANi: $\mathrm{H}_{2} \mathrm{SO}_{4}$ concentration ratio equals to $1: 5$. Moreover, the film exhibits highest optical contrast at the $3.0 \mathrm{~V}$ applied potential.

\section{ACKNOWLEDGMENT}

The authors wish to acknowledge the Center of Excellence in Materials Science and Technology, Faculty of Science and the Graduated School, Chiang Mai University for financial supports.

\section{REFERENCES}

[1] L. M. Huang, T. C. Wen, and A. Gopala, "Poly (2, 5-dimethoxyaniline) based electrochromic device," Materials Chemistry and Physics, vol. 77, pp. 726-733, Feb. 2002.

[2] A. Afzali, S. L. Buchwalter, L. P. Buchwalter, and G. Hougham, "Reaction of polyaniline with NMP at elevated temperatures," Polymer, vol. 38 no. 17, pp. 4439-4443, 1997.

[3] Y. Kung, S. K. Kim, and C. Lee, "Doping of polyaniline by thermal acid-base exchange reaction," Materials Science and Engineering C, vol. 24, pp. 39-41, 2004.

[4] D. Yang and B. R. Mattes, "Polyaniline emeraldine base in N-methyl-2-pyrrolidinone containing secondary amine additives: B. Characterization of solutions and thin films," Synthetic Metals, vol. 129, pp. 249-260, April 2002.

[5] T. C. Hueng, T. C. Yeh, H. Y. Huang, W. F. Ji, Y. C. Chou, W. I. Hung, J. M. Yeh, and M. H. Tsai, "Electrochemical studies on aniline-pentamer-based electroactive polyamide coating: Corrosion protection and electrochromic properties," Electrochimica Acta, vol 56, pp. 10151-10158, Aug. 2011.

[6] T. C. Hueng, T. C. Yeh, H. Y. Huang, W. F. Ji, T. C. Lin, C. A. Chen, T. I. Yang, and J. M. Yeh, "Electrochemical investigatios of the anticorrosive and electrochromic properties of electroactive polyamide," Electrochimica Acta, vol. 63, pp. 185-191, Dec. 2011.

[7] B. Suephatthima, "Physical an electrochromic properties of poly (2, 5-dimethoxy aniline) synthesized in oxalic, nitric, and hydrochloric 
acids," M.S. thesis, the Petroleum and Petrochemical College, Chulalongkorn Univ., Bankkok, Thailand, 2012.

[8] S. Kim, X. Kong, and M. Taya, "Electrochromic windows based on anodic electrochromic polymesitylenes containing 9H-carbazole-9ethanol moieties," Solar Energy Materials and Solar Cells, vol. 117, pp. 183-188, 2013

[9] F. Scheinmann, An Introduction and Spectroscopic Methods for the Identification of Organic Compounds, Pergamon Press, Oxford, vol. 1, 1970.

[10] T. L. A. Campos, D. F. Kersting, and C. A. Ferreira, "Chemical synthesis of polyaniline using sulphanilic acid as dopant agent into the reactional medium," Surface and Coatings Technology, vol. 122, pp. 3-5, 1999.

[11] B. H. Lee, H. J. Kim, and H. S. Yang, "Polymerization of aniline on bacterial cellulose and characterization of bacterial cellulose/ polyaniline nanocomposite films," Current Applied Physics, vol. 12, pp. $75-80$, May 2011

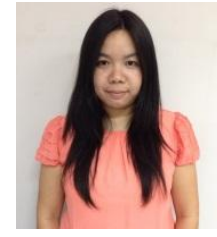

N. Thummarungsan was born in Chiang Mai Thailand on $4^{\text {th }}$ October, 1987. She received her bachelor's degree in Industrial Chemistry from Chiang Mai University, Thailand. At present, she is doing master's degree in Industrial Chemistry from Chiang Mai University, Thailand under the supervision of Dr. Datchanee Pattavarakorn.

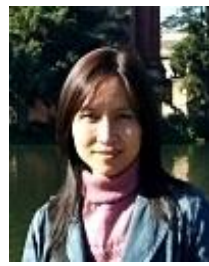

D. Pattavarakorn received $\mathrm{Ph}$.D. degree in Polymer Science from the Petroleum and Petrochemical College, Chulalongkorn University, Bangkok, Thailand in 2005. In present, she is the lecturer at Department of Industrial Chemistry, Faculty of science, Chiang Mai University, Chiang Mai, Thailand in the field of Polymer Technology. Her research interest includes conductive and electroactive polymers, biodegradation plastics and polymer composites. 